\title{
CARTAS A UMA NEGRA: UM ENCONTRO EPISTOLAR ENTRE FRANÇOISE EGA E CAROLINA DE JESUS
}

https://orcid.org/0000-0002-3628-0740 Maria de Fátima Machado A

${ }^{\text {A }}$ Universidade do Estado do Rio de Janeiro (Uerj), Rio de Janeiro, RJ, Brasil

Recebido em: 9 dez. 2021 | Aceito em: 19 jan. 2022 Correspondência: Maria de Fátima (negra.fa@hotmail.com)

FRANÇOISE, EGA. Cartas a uma negra. Tradução Vinicius Carneiro, Mathilde Moaty. São Paulo: Todavia, 2021. 252p.

O mais penoso para uma faxineira, eu acho, éo cheiro da vida dos outros.

Françoise Ega, 2021

O livro Cartas a uma negra, da escritora e ativista francesa Françoise Ega, nascida na Martinica, então colônia francesa, em 1920, e falecida em 1976, em Marselha, é a primeira obra da autora a ser traduzida para o português. Lançado no Brasil em 2021, pela editora paulista Todavia, cumpre o papel de apresentar a obra de Françoise Ega ao público leitor brasileiro. Escrito a partir do gênero epistolar, a escritora - mulher negra, moradora da periferia de Marselha e empregada doméstica - busca, através de cartas, chegar à escritora negra brasileira Carolina Maria de Jesus.

A partir de reportagens da Revista Francesa Paris Match, Françoise se reconheceu na história de Carolina Maria de Jesus, por também ser negra, pobre, empregada doméstica e viver na periferia, além de ter o nome semelhante ao da escritora brasileira, pontuando: "Eu também me chamo Marie, como você... (FRANÇOISE, 2021, p. 7)”. A obra não apresenta, em seu formato, introdução, capítulos, sumário e prefácio; divide-se em duas partes: a primeira termina na página 126 e a segunda começa na seguinte, somando um total de 252 páginas.

Retomando aos escritos de Françoise Ega no livro, como definir a beleza de uma carta que nunca será entregue? Ao se escrever para o outro, escreve-se para si mesmo? A sororidade que une mulheres da classe trabalhadora é capaz de ultrapassar os oceanos e aproximá-las a partir de lutas microbianas e anticapitalistas? Cartas a uma negra parece responder de forma afirmativa a tais perguntas. De maneira poética e contundente, narra o encontro de Ega, que vivendo o contexto de uma sociedade excludente na França, encontra no gênero epistolar sua 
forma de comunicação com a escritora Carolina Maria de Jesus, a qual nunca conhecera pessoalmente, mas que passa a conhecer a partir da leitura de seus escritos. Desta forma, para redigir suas vivências se inspira em Carolina de Jesus, que, como ela, buscava no tempo escasso e na criatividade o encontro com a escrita e a literatura, como forma de sobrevivência psíquica e material.

A autora, traduzida pela primeira vez em português postumamente, é uma das pioneiras da literatura de língua francesa da segunda metade do século XX. Ega faz parte das precursoras de autoras e autores originários de Guadalupe ou da Martinica, tornando-se um nome importante na literatura decolonial francesa.

Foi criada em um ambiente sem muitos recursos, juntamente com seus cinco irmãos. Seu pai era guarda-florestal, sua mãe costureira, e com a morte do pai sua mãe costurava para os vizinhos e vendia legumes da própria horta. $\mathrm{Na}$ juventude, em plena segunda Guerra Mundial, Ega viveu a experiência da ocupação da França pelos nazistas, a insubordinação das Antilhas ao regime Vichy, bem como o desembarque dos aliados com a libertação da França.

Casou-se com o militar de origem antilhana Franz Julian, em 1946. Em meados dos anos 1950, o casal passou a residir na periferia de Marselha, na França. Ega deixou a Martinica, com ensino médio completo e um diploma de datilografia. Com um curso técnico no currículo, não conseguiu emprego em sua área e, assim como a esmagadora maioria das antilhanas que viviam em Marselha, foi obrigada a trabalhar como faxineira para completar a renda familiar.

$\mathrm{O}$ racismo e o preconceito da sociedade francesa a impediram de obter o emprego desejado, e a frequência da discriminação que enfrentava fez com que Ega vivesse o ofício de mãe, trabalhadora doméstica, adiando o sonho de ser escritora. Deparou-se com a revista Paris Match no trajeto de ônibus para o trabalho, que comentava sobre a trajetória da escritora brasileira Carolina Maria de Jesus, mulher negra, favelada, que lançava seu livro Quarto de despejo, escrevendo-o com papel recolhido do lixo. Logo, Ega identificou-se com aquela que viveu durante quase toda a sua vida as mazelas do racismo, da exploração do trabalho e o desejo do reconhecimento de ser inserida na categoria de escritora.

Nessa leitura, Ega teve acesso ao percurso de Carolina, que é mostrado no referido artigo, desde seu início por meio de fotos da vida em extrema pobreza, bem como de Carolina de Jesus bem-vestida e com joias, em sua noite de autógrafos. Nascia desse encontro literário uma correspondência a uma destinatária que jamais responderia, mas que entenderia e seria cúmplice das reflexões políticas, econômicas e sociais dos contextos das experiências das mulheres negras faxineiras e empregadas domésticas. 
Sem prefácio, o livro inicia-se com o posfácio de Vinicius Carneiro e Maria-Clara Machado, apresentando uma abordagem crítica e biográfica da autora. Françoise Ega coloca em cada página uma data contendo, mês, dia e ano, marcando a temporalidade de sua escrita como elemento estrutural de uma carta dirigida a alguém que vai de maio de 1962 a 23 de junho 1964. A parte II do segue o mesmo modelo, dando desfecho explicativo às narrativas iniciadas anteriormente.

A primeira carta dirigida a Carolina de Jesus inicia-se com a seguinte indagação: "Pois é, Carolina, as misérias dos pobres do mundo inteiro se parecem como irmãs (FRANÇOISE, 2021, p. 5)". Ega faz uso dessa metáfora realista e descreve à amiga distante seu evento do dia, dos cinco dias de faxinas, a indiferença dos seus empregadores, que nunca perguntaram o seu nome nem pediram sua carteira de identidade.

Logo, Ega entrelaça o leitor, apresentando o comportamento do marido, que não a apoia em ser faxineira pelo fato de terem onde morar: "o importante é o pão de cada dia, o resto a gente dá um jeito" (FRANÇOISE, 2021, p. 7) Assim, dirige à Carolina o sentido literal do que o marido está dizendo. "Você conhece essas palavras. Na favela, você nunca foi capaz de pensar em nada além do pão de cada dia. Penso que é isso que me aproxima de você, Carolina Maria de Jesus. (FRANÇOISE, 2021, p. 7).

Explicita sua relação de afeto com os filhos: "as crianças estudam [...] me contam o enredo, detalhe por detalhe, da última história em quadrinhos que foi lida na escola" (FRANÇOISE, 2021, p. 7). A maternidade une remetente e destinatário em suas histórias reais, a construírem pelo conhecimento a libertação das prisões humanas, que são encarceradas na hierarquia de saberes. Mesmo tendo tanto em comum, sabe que nunca se encontrarão: "Carolina, você nunca vai me ler, eu jamais terei tempo de ler você." (FRANÇOISE, 2021, p.7)

Ela expõe os encontros com as mulheres que exercem a mesma função. "Carolina, ontem vi uma mocinha da minha raça chorando, ela me contou que pessoas a trouxeram, uma patroa pagou a minha viagem" (FRANÇOISE, 2021, p. 9). A posição política é um fato marcante durante vários trechos de cartas dirigidas à escritora brasileira. Constantemente preocupada com as condições legais das pessoas caribenhas que chegavam a Marselha, fazia seu papel de ativista e cidadã: "Como as coisas chegam a esse ponto? Foi feito um contrato de trabalho, seu nome está no sistema de seguridade social?” (FRANÇOISE, 2021, p. 10).

Narra as ações com patroas cruéis, adaptadas ao modelo serviçal. "Ela pega um tapete empoeirado e se põe a sacudi-lo justo no lugar que acabei de deixar brilhando!” Mas não desiste de dividir com a sociedade o que alguns sistemas econômicos produzem em seus contextos, "se 
ficar em casa, jamais poderei ver até que ponto a estupidez humana pode ir" (FRANÇOISE, 2021, p. 11). Desta maneira, Ega vivencia momentos difíceis na procura de trabalho, para que os invernos fossem menos frios com a neve se propunha a cair ano após anos.

A amizade criada por Ega com Carolina de Jesus sensivelmente a impulsiona a ter força e coragem de narrar fatos à amiga dos personagens reais da sua vida. "Carolina, que procura tábuas para o seu barraco, com suas crianças aos berros, está mais perto de mim" (FRANÇOISE, 2021, p. 7). Essa perspicácia literária prende o leitor no acompanhamento e nos desdobramentos como em um romance. "Para escrever alguma coisa, preciso esconder o meu lápis, senão as crianças somem com ele e com meus cadernos." Assim, ao apresentar seus personagens engendrados na família, amigos e trabalho, a autora escreve suas cartas não somente à Carolina, porque "Carolina" é uma de suas personagens, como também escreve fascinantemente aos seus futuros leitores.

Neste sentido, os relatos nas cartas são envolvidos por dores, alegrias, humilhações, ações políticas, porque sendo consciente de sua condição, se posiciona em ajudar as mulheres/homens Antilhanos que chegavam à França para viverem situações mais deploráveis do que a sua. Afinal, tinha um lar para retornar. "Carolina, sou uma privilegiada, quando deixar a patroa e seus panos de pó, tenho um abrigo, uma família à minha espera e mais trabalho do que se possa imaginar" (FRANÇOISE, 2021, p. 40).

Suas escritas à amiga eram, em sua maior parte, redigidas no ônibus sob olhares curiosos dos passageiros, ou quando terminava os afazeres domésticos, principalmente quando as crianças estavam dormindo. Constantemente, remetia a esclarecer as situações anteriores, por isso, por inúmeras vezes colocou sua insistência em enviar aos editores as suas produções.

Recebendo pouco incentivo, com mãos doloridas e calejadas pelos produtos de limpeza das casas onde fazia faxinas, encontrava apenas em sua insistência a coragem de quem escreve como um ato de respiro, um ânimo de viver em alguns instantes com boas gargalhadas. Pois eram nas palavras que existia o sentido, a sustentação, a denúncia a tantas injustiças sofridas.

Por tanto, ao pensar sobre suas experiências, seu entendimento político foi alçando voos mais profundos, transformando seus escritos em documentos literários de grande e fundamental importância. A circulação de seus escritos, suas posições políticas e anticoloniais ajudaram a construir novas perspectivas para pensar o seu tempo histórico, atravessando séculos em sociedades que ainda são adoecidas pelo processo colonial.

Cartas a uma negra nos traz a oportunidade de olharmos para nossa brasilidade e percebermos que pouco conhecemos da escritora Carolina Maria de Jesus. Que as escritoras 
negras que escrevem de seus lugares de percepções de existência são categorizadas, por vezes, pelo poder e pela "ignorância" literária, por ser ainda julgada a tessitura testemunhal como algo "menor", envolvida no preconceito linguístico, sendo considerada uma escrita de segunda classe. Contudo, essas escritas relatam, em sua profundidade, o racismo estrutural a que somos submetidos no Brasil.

Carolina Maria de Jesus, brasileira, mineira nascida em Sacramento em 1914, escritora, traduzida em quarenta e seis idiomas, em quase dezesseis países, provavelmente é a mulher negra mais publicada no mundo. Com sua escrita lancinante, poética, forte, a contrapelo, escancara a sociedade brasileira sociologicamente, politicamente, revelando, em seus diários, uma sociedade estruturalmente desigual, racista, cruel. E Ega a considera como uma irmã, relembrando-nos que os de "fora" nos veem mais que nós mesmos.

A obra de Marie, prenome de Françoise Ega, é um estímulo a todas as Marias, mulheres negras e pobres que buscam por meio da rebeldia, da política, da educação e da leitura infringir o que é institucionalizado. Porque a rebeldia, a luta política e o conhecimento são capazes de transcender as subordinações a que os povos excluídos são renegados e transformar seus caminhos para cidadãos/cidadãs, sujeitos construtores de suas histórias emancipatórias. Portanto, o uso da língua une, nesse tempo presente, três Marias, oriundas de famílias de mulheres negras faxineiras, entretanto vencedoras, que continuam na luta por uma sociedade mais igualitária.

Ao ler o livro Cartas a uma negra, despertamos em nós, mulheres negras, descendentes de povos escravizados, a coragem que temos de não desistir dos nossos projetos individuais e coletivos, na conquista dos direitos sociais que nos são negados. Porque ao nos libertamos, honramos os que vieram antes, conquistando espaços em campos como a universidade, para que trouxessem para a discussão a inclusão de uma literatura negra, pois ainda vivemos os resquícios de projetos políticos de branqueamento social, os quais educadores devem constantemente combater, haja vista os impactos objetivos e subjetivos de sua política de desmerecimento.

A obra de Marie, com sua poesia e força literária, acende em nós o desejo de compartilhar, em nosso cotidiano escolar, o prazer da escrita. A beleza e força de que o livro de Ega nos presenteia reflete o encontro com a luta e com a arte de viver com dignidade, fazendo de seus escritos modos de afirmação de uma ética e de uma estética que não aparta a poesia da vida cotidiana, traduzindo para o papel a sua vontade freirianamente de ser mais, de afirmar-se escritora.

Revista Interinstitucional Artes de Educar. Rio de Janeiro, V.8, N.1 - pág. 313-318 jan-maio de 2022: "Por uma pedagogia macunaímica” - DOI: 10.12957/riae.2022.65334 
O que Ega nos mostra é o encontro com o Outro em sua exuberante e complexa dimensão humana. Ao pensar o ritmo das cartas escritas por Ega, ressalta-se que, de modo geral, as pessoas não escrevem cartas no século XXI, principalmente porque a velocidade e voracidade das lógicas temporais e espaciais não possibilitam aos homens e às mulheres (pós)modernos essa experiência de encontro consigo mesmo que a escrita de uma carta proporciona.

Talvez o que de mais profundo e delicado reverbera na leitura do livro de Marie Françoise Ega seja justamente o gênero epistolar, o tom de suas cartas e o seu desejo de encontrar o leitor e enredá-lo. O que Ega parece nos dizer também é que não importa necessariamente o gênero literário de autores. Para a escritora, o importante é o processo e a intensidade da escrita, o diálogo travado consigo e com o Outro, aquele que a lê. Por certo, um diálogo comprometido com a liberdade, com a reflexão e com a emancipação humana não pode deixar de fora o deleite e fruição da importante e necessária obra literária Cartas a uma negra. 